\title{
Editorial
}

\section{Dr. Jorge Veiga de Cabo: Editor Científico para la Medicina y Enfermería del Trabajo}

\author{
Dr. Jorge Veiga de Cabo: Scientific Editor in Occupational Medicine \\ and Nursing
}

\author{
Jerónimo Maqueda-Blasco ${ }^{1,2,3}$ \\ 'INSST, Director del Departamento de Promoción de la Salud y Epidemiología, Madrid, España. \\ 2Instituto de Salud Carlos III. Escuela Nacional de Medicina del Trabajo, Exdirector, Madrid, España. \\ ${ }^{3}$ Comisión Nacional de la Espacialidad de Medicina del Trabajo, Vocal, España \\ Recibido: 13-07-2020 \\ Aceptado: 17-07-2020

\section{Correspondencia} \\ Jerónimo Maqueda Blasco \\ jeronimo.maqueda@insst.mites.gob.ee
}

La Gestión del Conocimiento Biomédico es un proceso complejo que nace fundamentalmente de la confluencia de tres bases: Competencia, Investigación y Comunicación y crece de la interacción mutua entre ellas, de tal manera que unas alimentan "a" las otras y a su vez se retroalimentan "de" las otras.

No se puede generar Competencia sino se crea ni se comunica el Conocimiento y, a su vez, la Competencia es condición previa a la Comunicación y al Conocimiento. Todo ello movilizado a partir de tres elementos instrumentales: la Formación, el Método científico y la Edición científica.

Durante estos últimos 15 años el principal tractor de la Edición y Divulgación Científica en Medicina del Trabajo en nuestro país ha sido el Dr. Veiga de Cabo, Editor de la Revista Medicina y Seguridad del Trabajo, revista fundada en 1952, decana en nuestro país de la comunicación científica en Medicina del Trabajo, cuya continuidad y fortalecimiento se debe al esfuerzo de un equipo editorial y de revisores liderados por él mismo.

Los que trabajamos en cualquier faceta de la Medicina del Trabajo hemos tenido la suerte de que el Dr. Veiga de Cabo se incorporara al Equipo de la Escuela Nacional Medicina del Trabajo hacia el año 2006. El Dr. Veiga de Cabo aportaba a ese Equipo su experiencia y "Know-how" como Director de la Biblioteca Nacional de Ciencias de la Salud, de la que fue parte muy activa en su creación: ideó y dirigió el proyecto de Biblioteca Virtual de Ciencias de la Salud y entre otras acciones lideró la creación del Índice Bibliográfico Español en Ciencias de la Salud (IBECS) y desarrolló el Catálogo Colectivo de Publicaciones Periódicas de las Bibliotecas de Ciencias de la Salud Españolas. Podemos concluir en la "evidencia" que sin sus aportaciones la divulgación y el acceso a la documentación Científica en Biomedicina en España estarían en un nivel inferior al actual.

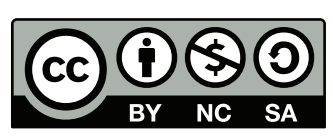

https://creativecommons.org/licenses/by-nc-sa/4.0/ 
Su incorporación a la Escuela Nacional de Medicina del Trabajo se produce en un momento de crisis interna que ponía en grave riesgo su continuidad, pero el Dr. Veiga de Cabo era un "hombre de retos" y unió sus esfuerzos a un equipo o, mejor dicho, "equipazo" de profesionales como la Dra. Ruiz Figueroa, la enfermera $M^{a}$ Fe Gamo, el Dr. Conde Salazar y posteriormente la Dra. Cortés Barragán que fueron capaces de situar de nuevo a la Escuela en el lugar de la Medicina y Enfermería del Trabajo que por historia y mérito le corresponde.

Esa complicada época alcanzó también a la Revista Medicina y Seguridad del Trabajo: el Dr. Veiga de Cabo asumió la responsabilidad de Editor y junto con la enfermera Isabel Mangas la Revista "desplegó velas", consiguió agregar apoyos como los de la Organización Panamericana de la Salud (OPS-OMS) que supusieron la internacionalización su Comité científico. Implantó un sistema de revisión por pares con un panel internacional de evaluadores y un procedimiento de evaluación normalizado, se dotó a la revista de unas normas de publicación que cumplían con los estándares internacionalmente de ediciones científicas.

El Dr. Veiga de Cabo, en un tiempo récord, consiguió un espacio editorial de calidad para comunicar internacionalmente la producción científica española en Medicina y Enfermería del Trabajo. La posterior y creciente adhesión de autores iberoamericanos convirtió a la revista en el espacio editorial más influyente internacionalmente en la comunicación científica en Medicina y Enfermería del Trabajo en idioma castellano.

En 2009 condujo el proceso de transformación digital de la Revista y su migración a un sistema de "Open Access" que contribuyó, sin lugar a dudas, a su reconocimiento nacional e internacional, siendo incluida en repertorios como DOAJ y SciELO e indizada en índices nacionales como IBECS, IME, CISDOC, DIALNET, e internacionalmente como LATIDEX y HINARI; este último supuso el reconocimiento de la Revista Medicina y Seguridad del Trabajo por la OMS como publicación de interés internacional de Investigación en Salud.

Todo gran profesional suele coincidir con una gran persona y eso, sobre todo lo demás, era Jorge.

Jorge como compañero y amigo fue maravilloso. Ante la incertidumbre y la duda siempre tenía un buen consejo, ante las dificultades, una solución y en la adversidad, una sonrisa.

De ADN luchador y optimista, así se enfrentó a la enfermedad, siempre siendo plenamente consciente del tiempo que no tenía, pero arañando ese tiempo a la enfermedad y sobreponiéndose al sufrimiento disfrutó de la tercera generación de su familia, fue luz para otros enfermos e irradió ánimos a los amigos.

Tu muerte, aun esperada, me dejó sin palabras, sin capacidad de reacción y sin aliento y por ello ahora, con algo más de sosiego, puedo recordar todo lo vivido en estos años de trabajo con ese privilegio que da el hacer el camino con alguien como tú al lado.

Jorge Amigo, gracias por haber sido. Jorge Editor, gracias por haber hecho. 